\title{
Silk derived formulations for accelerated wound healing in diabetic mice
}

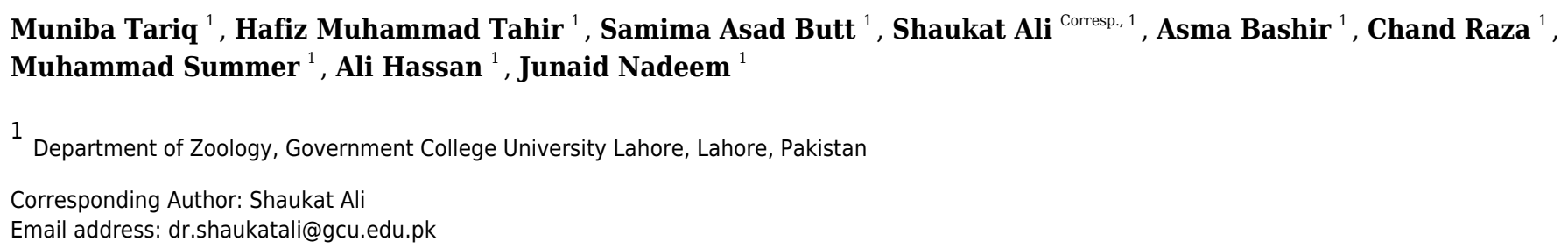

Background: The present study aimed to prepare effective silk derived formulations in combination with plant extract (Aloe vera gel) to speed up the wound healing process in diabetic mice. Methods: Diabetes was induced in albino mice by using alloxan monohydrate. After successful induction of diabetes in mice, excision wounds were created via biopsy puncture $(6 \mathrm{~mm})$. Wound healing effect of silk sericin $(5 \%)$ and silk fibroin (5\%) individually and in combination with $5 \%$ Aloe vera gel was evaluated by determining the percent wound contraction, healing time and histological analysis. Results: The results indicated that the best biocompatible silk combination was of $5 \%$ silk fibroin and $5 \%$ Aloe vera gel in which wounds were healed in 13 days with wound contraction: $98.33 \pm 0.80 \%$. In contrast, the wound of the control group (polyfax) healed in 19 day shaving $98.5 \pm 0.67 \%$ contraction. Histological analysis revealed that the wounds which were treated with silk formulations exhibited an increased growth of blood vessels, collagen fibers, and much reduced inflammation. Conclusion: It can be concluded that a combination of Bombyx mori silk and Aloe vera gel is a natural biomaterial that can be utilized in wound dressings and to prepare more innovative silk based formulations for speedy recovery of chronic wounds. 


\section{Silk derived formulations for accelerated wound healing in 2 diabetic mice}

3 Muniba Tariq, Hafiz Muhammad Tahir, Samima Asad Butt, Shaukat Ali*, Asma Bashir,

4 Chand Raza, Muhammad Summer, Ali Hassan, Junaid Nadeem

5 Department of Zoology, Government College University Lahore, Pakistan

6

*Corresponding Author: Medical Toxicology and Entomology Laboratory, Department of

8 Zoology, Government College University, Lahore, Pakistan, Email: dr.shaukatali@gcu.edu.pk.

9 Phone: +92(0)305-4190596. combination with plant extract (Aloe vera gel) to speed up the wound healing process in diabetic mice. Methods: Diabetes was induced in albino mice by using alloxan monohydrate. After successful induction of diabetes in mice, excision wounds were created via biopsy puncture $(6 \mathrm{~mm})$. Wound healing effect of silk sericin (5\%) and silk fibroin (5\%) individually and in combination with 5\% Aloe vera gel was evaluated by determining the percent wound contraction, healing time and histological analysis. Results: The results indicated that the best biocompatible silk combination was of $5 \%$ silk fibroin and $5 \%$ Aloe vera gel in which wounds were healed in 13 days with wound contraction: $98.33 \pm 0.80 \%$. In contrast, the wound of the control group (polyfax) healed in 19 day shaving $98.5 \pm 0.67 \%$ contraction. Histological analysis revealed that the wounds which were treated with silk formulations exhibited an increased growth of blood vessels, collagen fibers, and much reduced inflammation. Conclusion: It can be concluded that a combination of Bombyx mori silk and Aloe vera gel is a natural biomaterial that 
25

26

27

28

29

30

31

32

can be utilized in wound dressings and to prepare more innovative silk based formulations for speedy recovery of chronic wounds.

Keywords: Sericin, Fibroin, Skin wound, Silk, Diabetes, Aloe vera

\section{INTRODUCTION}

Cutaneous wound healing is a programmed, multifaceted and sequential biological process that relies on the interaction between a large number of cells and molecular factors to repair the barrier function of the skin (Paquette \& Falanga, 2002; Martínez-Mora et al., 2012). A 'wound' is the disruption of normal skin physiology, while 'wound healing' is the process the body pursues to restore skin stability (Sugihara et al., 2000). Ideal healing of a skin wound requires synchronized incorporation of all molecular and biochemical events of cell proliferation, migration, deposition of extracellular matrix and remodeling (Das \& Baker, 2016). However, this orderly advancement of the healing process is compromised in chronic, non-healing wounds (Falanga, 2005). Chronic wounds normally occur in diabetic patients due to their impaired wound healing process (Spampinato et al., 2020; Farman et al., 2020).

Diabetes is a prevalent health challenge that impacts people worldwide. It is recognized as a group of varied disorders with the common elements of glucose intolerance, hyperglycemia caused by insulin shortage, reduced efficacy of insulin action, or both (Albert \& Zimmet, 1998; Atlas, 2015). Non-healing chronic wounds are considered as one of the most serious complications of diabetes. Such complications are associated with an increased risk of bacterial infection, blood vessel and nerve injury, and ultimately amputation of limbs and other organs (Masood et al., 2019).

The wound healing process in diabetic patients is profoundly slow as compared to healthy individuals, hence prolonged healing duration increases the risk of wound associated 
48 infections (Menkeet al., 2007; Dehghani et al., 2020).The current wound healing investigations

49 signify the therapeutic potential of formulations in modulating the wound healing process and

50 reducing suffrage of patients (Nithya et al., 2011). Scientists have tried different chemicals and

51 herbal formulations to speed up wound healing in diabetic patients but there were certain

52 limitations and the results were not much persuasive.

There is a long history of utilization of natural materials in the biomedical industry.

Amongst many naturally occurring materials, silk obtained from silkworms is considered as an exceptional biomaterial which has a wide range of medical applications (Jastrzebska et al., 2015; Tahir et al., 2020; Elahi et al., 2020). It is classified as a 'model biomaterial' due to its remarkable mechanical strength (Vollrath \& Porter, 2006; Tahir et al., 2019), impressive biocompatibility with skin tissues, negligible immunogenicity (MacIntosh et al., 2008) and minimal bacterial adhesion (Cassinelli et al., 2006). Mounting evidence of preclinical research demonstrates excellent wound healing properties of silk proteins since the 1990s (Shailendra \& Das, 2019). Silk (particularly silkworm silk) started its journey in the biomedical industry when it was first used to suture skin wounds (Altman et al., 2003).

Silk is the strongest and most flexible naturally occurring fiber. It is smooth, shiny and soft in texture unlike most of the synthetic fibers (Altman et al., 2003). There are two proteins fibroin (80\%) and sericin (20\%) present in the silk thread which is secreted by Bombyx mori's silk glands (Pornanong, 2012; El-Fakharany., 2020). The middle and posterior silk glands of $B$ mori larvae produce a fibroin layer and three layers of sericin respectively (Zhou et al., 2000). Sericin and fibroin play an active role in accelerating wound healing (Li et al., 2020). The wound healing potential of sericin in cell culture and animal models is well reported (Aramwit \& Sangcakul, 2007). Successful trials with fibroin based biomaterials, for example sponges (Roh et 
71 al., 2006), hydrogels (Finiet al., 2005), films (Sugihara et al., 2000) and nanofibers mats

72 (Schneider et al., 2009) have been conducted with impressive results. It has also been reported

73 that silk based wound dressings stimulate cell proliferation and recruitment of cells such as

74 keratinocytes in the wound bed to accelerate the wound healing process (Chouhan \& Mandal,

75 2020). Scientists have prepared, silk fibroin/keratin-based biofilms to control the release rate of

76 elastase enzyme in the chronic wound milieu (Rohet al., 2006; Vasconcelos et al., 2010).

77 As silk fibroin and sericin exhibit unique biological and physical properties, they are extensively

78 explored by researchers in the biomedical industry for their utilization in wound healing

79 materials. The current study attempts to evaluate the silk-based formulations in treating induced-

80 skin wounds in diabetic mice model. The objectives of this study were to extract pure silk fibroin

81 and silk sericin from silkworm cocoons and to prepare silk-based formulations in combination

82 with plant extract i.e., Aloe vera gel. Furthermore, in vivo wound healing potential of silk based

83 formulations in artificially wounded diabetic mice model was also evaluated. 
85

86

87

88

89

\section{MATERIALS AND METHODS}

\section{Ethical statement}

All animal trial techniques were directed as per local and worldwide controls. The nearby direction is the Wet op de dierproeven (Article 9) of Dutch Law (International) as detailed in our previous studies (Ali et al., 2020a; Ali et al., 2020b; Hussain et al., 2020; Ara et al., 2020; Ali et al., 2019; Khan et al., 2019; Mumtaz et al., 2019; Mughal et al., 2019; Dar et al., 2019) and The Institutional Bioethics Committee at Government College University Lahore, Pakistan (No. GCU/IIB/21 dated: 08-01-2019).

\section{Rearing of mice in animal house}

The Swiss albino mice weighing around 29-30g and 8 weeks old were obtained from the Animal House, Department of Zoology, Government College University Lahore, Pakistan and used as experimental models. They were reared in standard plastic cages of length 10 inches, height 7 inches and width 5 inches in the same Animal House facility of Zoology Department, Government College University Lahore. Six mice were reared per cage under standard laboratory conditions (temperature $19-21{ }^{\circ} \mathrm{C}$, humidity $45-65 \%$ and $12 \mathrm{~h}$ light-dark cycle). They were fed standard animal diet and tap water in the cage. Mice were acclimatized for one week before the experimental procedures. The weight of each mouse was measured and noted throughout the experiment.

\section{Diabetes induction}

Alloxan and streptozotocin both are widely used diabetogenic agents, but alloxan was preferred over streptozotocin because it was easily available here at low cost. A single dose of alloxan monohydrate (CAT A7413-10G, Signa- Alrich, Germany) was injected intraperitoneally to induce type 1 diabetes. The dosage of alloxan monohydrate was freshly prepared in saline solution at a dosage of $200 \mathrm{mg} / \mathrm{kg}$ body weight (Ahmadi et al., 2012). All animals were fed with 
109 glucose solution (10\%) after receiving an injection of alloxan monohydrate to prevent them from

110 sudden hypoglycemic state (Vanitha et al., 2013; Bouzghaya et al., 2020). After 24 hrs of

111 induction of diabetes, blood samples were collected by pricking the tail tip of the mice. Blood

112 glucose level was measured with an electronic glucometer (On-call extra blood glucose meter

113 and test strips). Animals with a blood glucose level of $\geq 250 \mathrm{mg} / \mathrm{dl}$ were considered diabetic and

114 were selected for further experimentation (Chen et al., 2015). Mice were given free access to

115 food and water during the study and they were kept in standard plastic cages at room temperature

116 in the Animal House facility. Blood glucose levels of all albino mice were recorded before

117 starting of the experiment. Only those mice that have normal blood glucose levels were used for

118 further study and those having high blood glucose levels were excluded from the study (Dra et 119 al., 2019).

120

121

122

123

124

125

126

127

128

129

130

131

\section{Creation of skin excision wound in mice}

Mice were randomly divided into six groups with each group consisting of 6male mice. Animals were anesthetized intraperitoneally with ketamine $(100 \mathrm{mg} / \mathrm{kg})$ and Xylazine (10 $\mathrm{mg} / \mathrm{kg}$ ) in saline before wound induction. The dorsal fur of mice was shaved completely by using an electrical hand shaver. Two full thickness excision wounds were created on the dorsum of each mouse by using a $6 \mathrm{~mm}$ biopsy punch device. These surgical interventions were carried out under sterile conditions. The total surgical time was 15-20 minutes for each mouse. All animals received their respective treatments once a day from post wounding day till complete healing. Body weight, skin color and skin irritation were observed and recorded daily.

\section{Extraction of sericin from cocoons}

Silk cocoons of B. mori (silkworm) were kindly supplied by the Sericulture section of Forestry department, Punjab, Pakistan. These cocoons were sliced into small pieces. For sericin 
132 extraction, $5 \mathrm{~g}$ of silk cocoon pieces were immersed in $100 \mathrm{ml}$ of distilled water and autoclaved at $133121{ }^{\circ} \mathrm{C}$ and $15 \mathrm{lb}$ per square inch pressure for $1 \mathrm{hr}$. After $1 \mathrm{hr}$ the sericin solution was allowed to 134 cool at room temperature and then filtered through a filter paper. The filtration process removed 135 impurities from the sericin solution. The filtered sericin solution was subjected to lyophilizer 136 (freeze drying) at $-82{ }^{\circ} \mathrm{C}$ for $72 \mathrm{hrs}$ to obtain sericin powder (Martínez et al., 2017). Extraction 137 procedures of sericin and fibroin were carried out separately by utilizing fresh silk cocoons each 138 time.

\section{Extraction of fibroin}

Degumming: Silk cocoons synthesized by B. mori silkworms were soaked in warm water to loosen the threads. Silk threads from several cocoons were then unwound to obtain silk fibers. Raw silk fibers were then degummed in $0.5 \% \mathrm{NaHCO}_{3}$ at $100^{\circ} \mathrm{C}$ for $1 \mathrm{hr}$, rinsed thrice with distilled water and then dried overnight in oven $\left(60-80^{\circ} \mathrm{C}\right)(\mathrm{Ju}$ et al., 2016; Tahir et al., 2020). with constant stirring in a solvent system of calcium chloride: ethanol: distilled water in a molar ratio of 1:2:8 (Wang \& Zhang, 2013; Yi et al., 2018). Urea (8 mM) was also added to calcium chloride solvent to achieve 100\% dissolution of silk fibers (Min \& Lee, 2004). with a cellulose dialysis membrane in distilled water for 3days. After dialysis the silk fibroin solution was sonicated at $20 \mathrm{kHz}$ : $400 \mathrm{~W}$ for $1 \mathrm{hr}$ and then lyophilized to obtain silk fibroin powder (Ha \& Park, 2003; Siavashani et al., 2020). 


\section{SEM analysis of silk fibroin and silk sericin:}

155 Powdered samples of silk fibroin and silk sericin were subjected to SEM (Scanning

156

157

158

159

160

161

162

163

164

165

166

167

168

169

170

171

172

173

174

Electron Microscopy) (FEI NOVA 450 Nano SEM) (voltage $1000 \mathrm{kV}$ ) available at LUMS (Lahore University of Management Sciences). SEM analysis was done to estimate the approximate sizes of silk fibroin and sericin particles.

\section{Extraction of Aloe vera gel}

Fresh Aloe vera gel was extracted from the leaves of the plant. The pulp was scraped out from the leaves and blended into a smooth paste using a high-speed blender. The extracted gel was transferred into an airtight container and refrigerated $\left(4^{\circ} \mathrm{C}\right)$. This extraction was carried out under sterile conditions.

\section{GC-MS analysis of Aloe vera gel}

Aloe vera gel $(5 \mathrm{ml})$ extracted from the leaves was analyzed by GC-MS (Gas chromatography-Mass spectrometry) on a GC-MS equipment at Department of Chemistry, GC University Lahore. GC-MS analysis was performed to detect the bioactive compounds present in the Aloe vera gel. The parameters used in GC-MS analysis were Retention time (RT), I Time, F Time, Area, Area \%, Height, Height \%, A/H and Base (m/z).

\section{Preparation of formulations}

Gel formulations were prepared for four treatment groups. There were two control groups i.e., positive control in which wounds were treated with polyfax (Polyfax is a skin ointment with active ingredients Bacitracin zinc and Polymiyxin B sulphate. Both of these ingredients are antibacterial. This ointment is used for the treatment of infected surgical cuts, burns, infected 
175 wounds, infected ulcers on skin etc) and negative control in which wounds were washed with

176 saline solution (0.9\%) daily. All the groups are shown below:

T1 5\% Sericin

T2 5\% Sericin and 5\% Aloe vera gel

T3 5\% Fibroin

T4 5\% Fibroin and 5\% Aloe vera gel

C1 Positive control (Polyfax)

C2 Negative control (Saline solution)

\section{Sericin (5\%)} water. Sericin solution was added to the Na-CMC solution with constant stirring until it became

181 a homogenous gel (Ersel et al., 2016; Nishida et al., 2011).

\section{Fibroin (5\%)}

184 dissolved in distilled water to form a homogeneous solution. The fibroin solution (5\%) was

185 prepared in distilled water and added to the Na-CMC solution with constant stirring until the 186 solution became thick and homogenous (Nishida et al., 2011). 


\section{Sericin (5\%) and Aloe vera gel (5\%)}

Sericin solution (5\%) was prepared in distilled water, mixed with 5\% Aloe vera gel and

vortexed for 1 minute. The solution was stored in falcon tubes at low temperature $\left(4^{\circ} \mathrm{C}\right)$ to

190 prevent the growth of microorganisms.

\section{Fibroin (5\%) and Aloe vera gel (5\%)}

Fibroin solution (5\%) was prepared in distilled water and mixed with 5\% Aloe vera gel.

The solution was vortexed for 1 minute and stored at low temperature $\left(4^{\circ} \mathrm{C}\right)$ in falcon tubes.

194

195

196

197

198

199

200

201

202

203

204

205

\section{Application of gel formulations on wounds}

The diabetic mice were subjected to their respective treatments till complete wound healing. The formulations were applied evenly on the wound surface daily.

\section{Percent wound contraction}

After wound creation, the wound margins were traced at 2 days interval on transparent graph paper. Measurements were continued until the complete (98-99\%) wound restoration. After 2 days interval, the healed area was calculated. The contraction was represented as percent wound contraction and epithelialization time was observed after complete healing (Lodhi et al., 2016).

The rate of healing as percentage contraction was calculated using the formula:

$=\underline{\text { Initial wound area-Wound area on a specific day }} \times 100$

Initial wound area 
206

207

208

209

210

211

212

213

214

215

216

217

218

219

220

221

222

223

224

225

226

\section{Histological evaluations}

Skin sample of one mouse from each group was acquired at post wounding day 5 and 10 . The central portion of tissue was fixed in $10 \%$ buffered formalin $(\mathrm{pH}=7)$. Thin sections were prepared using a microtome and stained with hematoxylin-eosin and Masson's trichrome method. Wound healing effects were examined histologically under a light microscope using low power magnification (Aramwit \& Sangcakul, 2007).

\section{Euthanization and Dissection of animals}

For euthanization, mice were placed in beakers and euthanized with a large piece of cotton soaked in chloroform. Beaker was covered properly with an aluminum foil. The mice were euthanized within 10-15 minutes. All euthanized mice were dissected and then skin samples were collected for histological evaluation.

\section{Statistical evaluations}

For statistical analysis, the normality of the data was assessed using Shapiro-Wilk's test. One-way ANOVA was conductedout to compare percent wound contractionin control and treatment groups, followed by Tukey's post-hoc test using SPSS software (version 20). All data were expressed as the mean \pm SEM.

\section{RESULTS}

\section{TEM analysis of silk fibroin and silk sericin}

The transmission electron micrographs (TEM) showed 240-300 nm sized silk fibers of sonicated samples (Figure 1). TEM micrographs of silk sericin at $2 \mu \mathrm{m}$ scale bar are shown in Figure 1. Results of TEM indicated that the size of the of silk sericin particles is approximately $102.5 \mathrm{~nm}$. 


\section{GC-MS analysis of Aloe vera gel}

228 A total of seventeen compounds were detected in Aloe vera gel by GC-MS analysis (Table 1).

229 Five major compounds (2,4:3,5:6,7-Tri-O-benzylidene-1-deoxy-d-gluco-d-gulo-heptitol, 230 stannane bis diphenyl, isopropyl myristate, 9-Octadecenoic acid and 10-Octadecenoic 231 acid)identified in Aloe vera gel. Their molecular formula, molecular weight (MW), retention 232 time (RT) and peak area (\%) are presented in Table 2.Detail of major and minor compounds 233 (Table 1 and Table 2) detected through GC-MS analysis of Aloe vera gel will be helpful in future 234 wound healing studies and they may be utilized individually or in combinations for preparing 235 more effective gel formulations to treat chronic wounds.

236

237 238

\section{Assessment of wound contraction}

Healing area of wounds in treatment and control groups at day 11 is presented in figure 2 and at different days as percent wound contraction in Figure 3.

\section{Percent wound contraction at various days}

Overall, there was significant difference in percent wound contraction between the treatment and control groups at day $3\left(\mathrm{~F}_{5,30}=3.391 ; \mathrm{P}=0.015\right)$, day $7\left(\mathrm{~F}_{5,30}=7.561 ; \mathrm{P}<0.001\right)$ and day $11\left(\mathrm{~F}_{5,30}=29.19 ; \mathrm{P}<0.01\right)$. There is a non-significant variation in percent wound contraction between $\mathrm{T} 1$ (5\% sericin) and $\mathrm{C} 1$ (positive control; polyfax) (P>0.05 ANOVA) at day 3 . However, there was a significant difference in percent wound contraction on day 3 between T3 (5\% fibroin) and $\mathrm{C} 1$ (positive control; polyfax) ( $\mathrm{P}=0.043$ ANOVA).

At day 7 results of Tukey's test indicated that group C1 (positive control; polyfax) differs non-significantly from $\mathrm{T} 1$ (5\% sericin) $(\mathrm{P}>0.05$ ANOVA) and $\mathrm{T} 2(5 \%$ sericin and 5\% Aloe vera $)(\mathrm{P}>0.05$ ANOVA). On the other hand, there was a significant difference between T3 (5\% 
249 fibroin) and $\mathrm{C} 1$ (positive control; polyfax) $(\mathrm{P}=0.037)$. At day 11 results of Tukey's test showed

250 that group $\mathrm{C} 1$ (positive control; polyfax) differs significantly from $\mathrm{T} 3$ (5\% fibroin) $(\mathrm{P}=0.013$

251 ANOVA) and T4 (5\% fibroin and 5\% Aloe veragel) $(\mathrm{P}<0.01$ ANOVA) in percent wound

252 contraction (Figure 3). However, the group C1 (positive control; polyfax) differs non-

253 significantly from T1 (5\% sericin) (P>0.05 ANOVA) and T2 (5\% sericin and 5\% Aloe vera)

254 (P>0.05 ANOVA).

255 Histological analysis

Images of wound size in different treatment and control groups at post wounding day 10

257 is shown in Figure 4. Best histological results were observed in group T4 (5\% fibroin and 5\%

258 Aloe vera gel) in which the formation of the new epidermis was initiated and dermis with blood

259 vessels and hair follicles were observed at post wounding day 10. However, histological results

260 from group C1 (positive control; polyfax) showed the formation of collagen fibers and formation

261 of thin epithelium and dermis at post wounding day 10. Healing of wound was incomplete

262 untilday 10 in positive control. In the group C2 (negative control; saline solution) there were

263 inflammatory cells and adipose tissues at post wounding day 10.

264 Histological examination of wounded tissues from group T1 (5\% sericin) showed the

265 formation of the new epithelial layer. The wound was not completely epithelialized till day 10

266 and inflammatory cells were also observed. The histology of wound at 100X of group T2

267 (i.e., 5\% sericin and 5\% Aloe vera gel) showed adipose tissues and new epithelium and formation

268 of new blood vessels and dermis at day 10. The histology of wound from group T3 (5\% fibroin)

269 showed an uneven epidermal surface. However, the epidermal surface became even and no

270 ulceration was observed on day 10 (Figure 4). 


\section{DISCUSSION}

273 In the present study, the potential of silk-based formulations to accelerate the wound

274 healing process in diabetic mice was investigated. The results of this study indicated that silk

275 sericin and fibroin when blended with Aloe vera gel quicken the healing process without causing 276 any allergic reactions.

The wounds treated with 5\% silk fibroin and 5\% Aloe vera gel showed 85\% healing in 11 days, however; wounds treated with 5\% silk sericin and 5\% Aloe vera gel showed $85 \%$ healing in 15 days. The results of wound healing treated with 5\% silk sericin and 5\%Aloe vera gel are comparable with findings of Aramwit and Sangcakul (2007) that 8\% sericin cream significantly reduced wound healing time. Conversely, wounds treated with cream base healed in 15 days. Moreover, Lamboni et al. (2015) also reported that the incorporation of silk sericin in wound healing materials forms an exceptional biomaterial that stimulates re-epithelialization by improving the rate of migration, adhesion, growth of keratinocytes, fibroblasts and increased production of collagen at the wound site.In a clinical trial, Aramwitet al. (2013) utilized 8\% sericin combined with silver sulfadaizine cream (standard antibiotic cream) to treat open wounds caused by second-degree burns. Outcomes of the study showed that the average healing time of wounds was significantly shorter in the treatment group compared to the control group (silver sulfadaizine without sericin).

Silk based films are considered safe and non-immunogenic biomaterial. The application of silk-based formulation on the skin does not affect serum profile since silk biofilm possess admirable biocompatibility with skin tissues. As it is infection-resistant in nature, it is regarded as an innovative wound coagulant biomaterial (Padol et al., 2011). The current study also 
294 indicated that silk proteins (sericin and fibroin) based formulations do not cause any skin

295 irritation, infection, or allergy when applied topically on wounds of diabetic mice.

296 Kanokpanont et al. (2013) created a silk fibroin based bi-layered wound dressing. Silk

297 fibroin woven fabric coated with wax was taken as a non-adhesive layer whereas the sponge

298 composed of silk sericin and glutaraldehyde-crosslinked silk fibroin/gelatin was fabricated as a

299 bioactive layer. Treatment of wounds with bi-layered wound dressings exhibited the greater

300 potential of wound reduction, increased epithelialization, and collagen formation when compared

301 with clinically available wound dressings. Hence this bi-layered wound dressing is considered as

302 an excellent candidate for healing full-thickness skin wounds. Similarly, in another experiment

303 Baygar (2020) investigated the synergistic effect of propolis and biogenic metallic nanoparticles

304 in combination with silk sutures for biomedical use. It was observed that silk sutures coated with

305 propolis and biogenic AgNPs showed potent antibacterial potential besides providing wound

306 healing activity and biocompatibility. In the present study, sericin and fibroin were applied

307 individually as well as in combination with Aloe vera gel on excision wounds in diabetic mice.

308 The results indicated that 5\% fibroin when mixed with 5\% Aloe vera gel showed the best results

309 among all treatment groups. Healing time till 85\% wound contraction was reduced as compared

310 to the control group (polyfax) 15-17 days. These findings suggest that silk can be amalgamated

311 with other natural products like plant extracts to make it biogenic and to improve its medicinal

312 properties.

Aloe vera is a medicinal plant that is widely being explored by scientists for its natural

314 healing ability for skin and other delicate tissues (Jadhavet al., 2020). Earlier studies showed that

315 one or more components of Aloe vera stimulate wound healing in different animal models 
316 (Gallagher and Gray, 2003). Chithra et al. (1998) analyzed the effects of Aloe vera gel on full

317 thickness wounds in diabetic rats. Their results revealed that treatment with Aloe vera gel speeds

318 up the wound healing process by increasing the rate of collagen synthesis, affecting fibroplasia

319 and wound size reduction. In another study, Maenthaisonget al. (2007) evaluated the

320 effectiveness of Aloe vera in burn wounds. Aloe vera was observed to increase the rate of re-

321 epithelialization and reduce the wound healing period for burn wounds. The results of the current

322 research have also showed that the treatment groups in which silk protein (fibroin) was combined

323 with Aloe vera gel showed greater wound healing potential as compared to a positive control

324 (polyfax). This combination of silk and plant extract was also observed to be most biocompatible

325 as compared to other treatment groups because no inflammation or ulceration was observed on

326 the skin of diabetic mice during the experiment.

\section{Conclusion}

328 The results of this study suggests that silk based formulations can be utilized in wound

healing materials because they are biocompatible, non-immunogenic and reduce wound healing time. This potential of silk-based formulations prepared in combination with Aloe vera gel has not previously been explored. Although the current research demonstrated the potential of silk derived formulations for wound healing in diabetic mice, the underlying molecular factors and events influencing wound healing are yet to be explored. Still, further studies need to be conducted to pinpoint how silk proteins influence the molecular events involved in the wound patients suffering from chronic wounds along with a reduction in their health care costs.

\section{Competing interests}

338 The authors declare that they have no competing interests 
339

340

341

342

343

344

345

346

347

348

349

350

351

352

353

354

355

356

357

358

359

360

361

362

363

364

365

366

367

\section{REFERENCES}

Ahmadi S, Ebrahimi S.S, Oryan S, Rafieenia F. 2012. Blockades of ATP-sensitive potassium channels and L-type calcium channels improve analgesic effect of morphine in alloxan-induced diabetic mice. Pathophysiology 19(3):171-177.

Alberti, K.G.M.M, Zimmet P.Z. 1998. Definition, diagnosis and classification of diabetes mellitus and its complications. Part 1: diagnosis and classification of diabetes mellitus. Provisional report of a WHO consultation. Diabetic Medicine 15(7):539-553.

Ali, S., Ejaz, M., Dar, K.K., Nasreen, N., Ashraf N, Gillani SF, Shafi N, Safeer S, Khan MA, Andleeb S, Mughal TA. 2020a. Evaluation of chemopreventive and chemotherapeutic effect of Artemisia vulgaris against diethylnitrosamine induced hepatocellular carcinogenesis in Balb C mice. Braz J Biol 80(3): 489-496.

Ali S, Awan Z, Mumtaz S, Shakir HA, Ahmad F, Tahir HM, Ulhaq M. 2020b. Cardiac toxicity of heavy metals (cadmium and mercury) and pharmacological intervention by vitamin $\mathrm{C}$ in rabbits. Environ Sci Pollut Res Int 27(23):29266-29279.

Ali S, Hussain S, Khan R, Mumtaz S, Ashraf N, Andleeb S, Shakir HA, Tahir HM, Khan MKA, Ulhaq M. 2019. Renal toxicity of heavy metals (cadmium and mercury) and their amelioration with ascorbic acid in rabbits. Environ Sci Pollut Res Int 26(4):3909-3920.

Altman G.H, Diaz F, Jakuba C, Calabro T, Horan R.L, Chen, J, Lu H, Richmond J, Kaplan D.L. 2003.Silk-based biomaterials. Biomaterials 24(3):401-416.

Aramwit P, Sangcakul, A. 2007. The effects of sericin cream on wound healing in rats. Bioscience Biotechnology and Biochemistry 71(10):2473-2477.

Ara C, Asmatullah, Butt N, Ali S, Batool F, Shakir HA, Arshad A. 2020. Abnormal steroidogenesis, oxidative stress and reprotoxicity following prepubertal exposure to butyl paraben in mice and protective effect of Curcuma longa. Environ Sci Pollut DOI: 10.1007/s11356-020-10819-8.

Aramwit P, Siritientong T, Srichana T. 2012.Potential applications of silk sericin, a natural protein from textile industry by-products. Waste Management and Research. 30(3):217-224.

Atlas D. 2015. International Diabetes Federation: IDF. Diabetes Atlas, 7th ed. Brussels, Belgium. 
368 Baygar T. 2020. Characterization of silk sutures coated with propolis and biogenic silver 369 nanoparticles (AgNPs); an eco-friendly solution with wound healing potential against surgical 370 site infections (SSIs). Turkish Journal of Medical Sciences, 50(1), pp.258-266.

371 Bouzghaya S, Amri M, Homblé F. 2020.Improvement of Diabetes Symptoms and

372 Complications by an Aqueous Extract of Linum usitatissimum (L.) Seeds in Alloxan-Induced 373 Diabetic Mice. Journal of Medicinal Food, 00(0):1-6.DOI: 10.1089/jmf.2019.0205

374 Cassinelli C, Cascardo G, Morra M, Draghi L, Motta A, Catapano G. 2006. Physical375 chemical and biological characterization of silk fibroin-coated porous membranes for medical 376 applications. The International Journal of Artificial Organs 29(9):881-892.

377 Chen T, Gao J, Xiang P, Chen Y, Ji J, Xie P, Wu H, Xiao W, Wei Y, Wang S, Lan L. 2015. 378 Protective effect of platycodin D on liver injury in alloxan-induced diabetic mice via regulation 379 of Treg/Th17 balance. International Immunopharmacology 26(2):338-348.

380 Chouhan D, Mandal B.B. 2020. Silk biomaterials in wound healing and skin regeneration 381 therapeutics: From bench to bedside. Acta Biomaterialia 103:24-51.

382 Chithra P, Sajithlal G.B, Chandrakasan G. 1998. Influence of Aloe vera on the healing of 383 dermal wounds in diabetic rats. Journal of Ethnopharmacolgy 59(3):195-201.

384 Chouhan D, Chakraborty B, Nandi S.K, Mandal B.B. 2017.Role of non-mulberry silk fibroin 385 in deposition and regulation of extracellular matrix towards accelerated wound healing.Acta 386 Biomaterialia 48:157-174.

387 Dar KK, Ali S, Ejaz M, Nasreen S, Ashraf N, Gillani SF, Shafi N, Safeer S, Khan MA4, Andleeb 388 S, Mughal TA. 2019. In vivo induction of hepatocellular carcinoma by diethylnitrosoamine and 389 pharmacological intervention in balb c mice using Bergeniaciliata extracts. Braz J Biol, 390 79(4):629-638

391 Das S, Baker A.B. 2016. Biomaterials and nanotherapeutics for enhancing skin wound healing. 392 Frontiers in Bioengneering and Biotechnology 4:82.

393 Dra L.A, Sellami, S, Rais H, Aziz F, Aghraz A, Bekkouche K, Markouk M, Larhsini M. 394 2019. Antidiabetic potential of Carallumaeuropaea against alloxan-induced diabetes in mice. 395 Saudi Journal of Biological Sciences 26(6):1171-1178.

396 Dehghani S, Dalirfardouei R, Jafari Najaf Abadi M.H, Ebrahimi Nik M, Jaafari M.R, 397 Mahdipour E. 2020. Topical application of curcumin regulates the angiogenesis in 
398 diabetic-impaired cutaneous wound. Cell Biochemistry and Function 38 (5): 558-566. DOI: $399 \quad 10.1002 /$ cbf.3500

400 Dra L.A, Sellami, S, Rais H, Aziz F, Aghraz A, Bekkouche K, Markouk M, Larhsini M. 401 2019. Antidiabetic potential of Carallumaeuropaea against alloxan-induced diabetes in mice. 402 Saudi Journal of Biological Sciences 26(6):1171-1178.

403 Elahi E, Ali S, Tahir H.M, Mushtaq R, Bhatti M.F. 2020. Sericin and fibroin 404 nanoparticles-Natural product for cancer therapy: A comprehensive review. International 405 Journal of Polymeric Materials and polymeric Biomaterials. In press. 406 DOI.10.1080/00914037.2019.1706515

407 El-Fakharany, E.M, Abu-Elreesh G.M, Kamoun E.A, Zaki S, Abd-EL-Haleem D.A. 2020. 408 In vitro assessment of the bioactivities of sericin protein extracted from a bacterial silk-like 409 biopolymer. RSC Advances, 10(9):5098-5107.

410 Ersel M, Uyanikgil Y, Akarca F.K, Ozcete E, Altunci Y.A, Karabey F, Cavusoglu T, Meral 411 A, Yigitturk G, Cetin E.O. 2016. Effects of silk sericin on incision wound healing in a dorsal 412 skin flap wound healing rat model. Medical science monitor: International Medical Journal of 413 Experimental and Clinical Research, 22, pp.1064.

414 Falanga, V. 2005. Wound healing and its impairment in the diabetic foot. The Lancet., 415 366(9498):1736-1743.

416 Farman N, Palacios-Ramirez R, Sbeih M, Behar-Cohen F, Aractingi S, Jaisser F. 2020.

417 Cutaneous wound healing in diabetic mice is improved by topical mineralocorticoid receptor 418 blockade. Journal of Investigative Dermatology, 140(1):223-234.

419 Farokhi M, Mottaghitalab F, Fatahi Y, Khademhosseini A, Kaplan D.L. 2018. Overview of 420 silk fibroin use in wound dressings. Trends in Biotechnology 36(9):907-922.

421 Fini M, Motta A, Torricelli P, Giavaresi G, Aldini N.N, Tschon M, Giardino R, Migliaresi 422 C. 2005. The healing of confined critical size cancellous defects in the presence of silk fibroin 423 hydrogel. Biomaterials 26(17):3527-3536.

424 Gallagher J, Gray, M. 2003. Is Aloe vera effective for healing chronic wounds? Journal of 425 Wound Ostomy and Continence Nursing. 30(2):68-71.

426 Ha S.W, Park Y.H, Hudson S.M. 2003. Dissolution of Bombyx mori Silk Fibroin in the 427 Calcium Nitrate Tetrahydrate- Methanol System and Aspects of Wet Spinning of Fibroin 428 Solution. Biomacromolecules 4(3):488-496. 
429 Hussain S, Ali S, Mumtaz S, Shakir HA, Ahmad F, Tahir HM, Ulhaq M. 2020. Dose and 430 duration-dependent toxicological evaluation of lead acetate in chicks. Environ Sci Pollut Res 431 27(13):15149-15164.

432 Jastrzebska K, Kucharczyk K, Florczak A, Dondajewska E, Mackiewicz A, Dams433 Kozlowska, H. 2015.Silk as an innovative biomaterial for cancer therapy. Reports of Practical 434 Oncology \& Radiotherapy 20(2):87-98.

435 Jadhav A.S, Patil O.A, Kadam S.V, Bhutkar M.A. 2020. Review on Aloe Vera is used in 436 Medicinal Plant. Asian Journal of Research in Pharmaceutical Science, 10(1):26-30.

437 Ju H, W, Lee O. J, Lee J. M, Moon B. M, Park H. J, Park Y. R, Park C. H. 2016. Wound 438 healing effect of electrospun silk fibroin nanomatrix in burn-model. International journal of 439 biological macromolecules, 85:29-39.

440 Kanokpanont S, Damrongsakkul S, Ratanavaraporn J, Aramwit, P. 2013. An innovative bi441 layered wound dressing made of silk and gelatin for accelerated wound healing. International 442 Journal of Pharmaceutics 436(1-2):141-153.

443 Khan R, Ali S Mumtaz M, Andleeb S, Ulhaq M, Tahir HM, Khan MKA, Khan MA, Shakir HA. 444 2019. Toxicological effects of heavy metals (cadmium and mercury) on blood and thyroid gland 445 and pharmacological intervention by vitamin c in rabbits. Environ SciPollut Res Int, 446 26(16):16727-16741

447

448 proteins for biomedical applications: Bioengineering perspectives. Progress in Polymer Science 449 39(2):251-267.

450 Lamboni, L, Gauthier M, Yang G, Wang Q. 2015. Silk sericin: a versatile material for tissue 451 engineering and drug delivery. Biotechnology Advances 33(8):1855-1867.

452 Li Z, Song J, Zhang J, Hao K, Liu L, Wu B, Zheng X, Xiao B, Tong X, Dai F. 2020.Topical 453 application of silk fibroin-based hydrogel in preventing hypertrophic scars. Colloids and 454 Surfaces B: Biointerfaces, 186:110735.DOI: 10.1016/j.colsurfb.2019.110735

455 Li S, Li L, Guo C, Qin H, Yu X. 2017. A promising wound dressing material with excellent 456 cytocompatibility and proangiogenesis action for wound healing: Strontium loaded Silk 457 fibroin/Sodium alginate (SF/SA) blend films. International Journal of Biological 458 Macromolecules 104:969-978. 
459 Lodhi S, Jain A.P, Rai G, Yadav A.K. 2016. Preliminary investigation for wound healing and

460

461

462

463

464

465

466

467

468

469

470

471

472

473

474

475

476

477

478

479

480

481

482

483

484

485

486

487

488

489

anti-inflammatory effects of Bambusa vulgaris leaves in rats. Journal of Ayurveda and Integrative Medicine 7(1):14-22.

Martínez D. C. C, Zuluaga C. L, Restrepo-Osorio A, Álvarez-López C. 2017. Characterization of sericin obtained from cocoons and silk yarns. Procedia engineering 200: 377-383.

Masood N, Ahmed R, Tariq M, Ahmed Z, Masoud M.S, Ali I, Asghar R, Andleeb A, Hasan A. 2019. Silver nanoparticle impregnated chitosan-PEG hydrogel enhances wound healing in diabetes induced rabbits. International journal of pharmaceutics, 559:23-36.

MacIntosh A.C, Kearns V.R, Crawford A, Hatton P.V. 2008. Skeletal tissue engineering using silk biomaterials. Journal of tissue engineering and regenerative medicine, 2(2-3): pp.7180 .

Maenthaisong R, Chaiyakunapruk N, Niruntraporn S, Kongkaew C. 2007. The efficacy of Aloe vera used for burn wound healing: a systematic review. Burns., 33(6):713-718.

Martínez-Mora C, Mrowiec A, García-Vizcaíno E.M, Alcaraz A, Cenis J.L, Nicolás F.J. 2012. Fibroin and sericin from Bombyx mori silk stimulate cell migration through upregulation and phosphorylation of c-Jun. PloS one 7(7): e42271.

Menke N.B, Ward K.R, Witten T.M, Bonchev D.G, Diegelmann R.F. 2007.Impaired wound healing. Clinics in Dermatology, 25(1):19-25.

Min B.M, Lee G, Kim S.H, Nam Y.S, Lee T.S, Park W.H. 2004. Electrospinning of silk fibroin nanofibers and its effect on the adhesion and spreading of normal human keratinocytes and fibroblasts in vitro. Biomaterials 25(7-8):1289-1297.

Mughal TA, Saleem MZ, Ali S, Anwar KK Bashir MM, Babar M, Khan MA. 2019. Evaluation of hepatotoxicity of carbon tetrachloride and pharmacological intervention by vitamin $\mathrm{E}$ in balb c mice. Pak J Zool, 51(2):755-761.

Mumtaz S, Ali S Khan R, Andleeb S, Ulhaq M, Khan MA, Shakir HA. 2019. The protective role of ascorbic acid in the hepatotoxicity of cadmium and mercury in rabbits. Environ SciPollut Res Int, 26(14):14087-14096.

Nishida A, Yamada M, Kanazawa T, Takashima Y, Ouchi K, Okada H. 2011.Sustainedrelease of protein from biodegradable sericin film, gel and sponge.International Journal of Pharmaceutics 407(1-2): 44-52. 
490 Nithya V, Brinda P, Anand K.V. 2011. Wound Healing activity of Leonotisnepetaefolia r. br., 491 in wistar albino rats. Asian Journal of Pharmaceutical and Clinical Research 4(2):23-26.

492 Padol A.R, Jayakumar K, Shridhar N.B, Swamy H.N, Swamy M.N, Mohan K. 2011.Safety 493 evaluation of silk protein film (a novel wound healing agent) in terms of acute dermal toxicity, 494 acute dermal irritation and skin sensitization. Toxicology International 18(1):17-21

495 Paquette D, Falanga V. 2002. Leg ulcers. Clinics in Geriatric Medicine 18(1): 77-88.

496 Raja S.K, Garcia M.S, Isseroff R.R. 2007. Wound re-epithelialization: modulating 497 keratinocyte migration in wound healing. Frontiers in Bioscience 12(3):2849-2868.

498

Roh D.H, Kang S.Y, Kim J.Y, Kwon Y.B, Kweon H.Y, Lee K.G, Park Y.H, Baek R.M, Heo

499

C.Y, Choe J, Lee J.H. 2006. Wound healing effect of silk fibroin/alginate-blended sponge in

500 full thickness skin defect of rat. Journal of Materials Science 17(6):547-552.

Siavashani A.Z., Mohammadi J., Rottmar M., Senturk B., Nourmohammadi J., Sadeghi B,

Huber L, Maniura-Weber K. 2020. Silk fibroin/sericin 3D sponges: The effect of sericin on structural and biological properties of fibroin. International Journal of Biological Macromolecules 153:317-326. of Impaired Wound Healing in Diabetes: Looking among Old Drugs. Pharmaceuticals 13(4):60. Schneider A, Wang X.Y, Kaplan D.L, Garlick J.A, Egles, C. 2009.Biofunctionalized electrospun silk mats as a topical bioactive dressing for accelerated wound healing. Acta Biomaterilia 5(7):2570-2578.

510 Shailendra S.S, Das, N. 2019. Silk Fibroin in effective wound dressing: An overview. International Journal of Advanced Research 7(4):68-72.

512 Sugihara A, Sugiura K, Morita H, Ninagawa T, Tubouchi K, Tobe R, Izumiya M, Horio T,

513 Abraham N.G, Ikehara S. 2000. Promotive effects of a silk film on epidermal recovery from 514 full-thickness skin wounds (44552). Proceedings of the Society for Experimental Biology and 515 Medicine 225(1):58-64.

516 Tahir H.M, Saleem F, Ain Ali S.Q, Summer M, Mushtaq R, Zahid M.T, Liaqat I, Murtaza 517 M. 2020. Synthesis of sericin-conjugated silver nanoparticles and their potential antimicrobial 518 activity. Journal of Basic Microbiology 60(5);458-467.

519 Tahir H.M, Jabeen J, Raza R, Ali S. 2019. Silk of Spider and Bombyx mori: An Overview. 520 Punjab Univ. J. Zool., 34(2): 170-179. 
521 Vanitha M, Karthikeyan J. 2013.Evaluation of Aloe vera gel for its anti- inflammatory activity

522 in diabetes mellitus using animal model system. International Journal of Drug Development and 523 Research, 5(1).305-309.

524 Vasconcelos A, Pêgo A.P, Henriques L, Lamghari M, Cavaco-Paulo A. 2010. Protein

525 matrices for improved wound healing: elastase inhibition by a synthetic peptide model.

526 Biomacromolecules., 11(9):2213-2220.

527 Vepari C, Kaplan, D.L. 2007.Silk as a biomaterial. Progress in Polymer Science 32(8-9):9915281007.

529 Vollrath F, Porter D. 2006.Spider silk as a model biomaterial. Applied Physics. A 82(2):205530212.

531 Wang H.Y, Zhang Y.Q. 2013.Effect of regeneration of liquid silk fibroin on its structure and 532 characterization. Soft Matter 9(1):138-145.

533 Yi B, Zhang H, Yu Z, Yuan H, Wang X, Zhang Y. 2018. Fabrication of high performance silk 534 fibroin fibers via stable jet electrospinning for potential use in anisotropic tissue 535 regeneration. Journal of Materials Chemistry B, 6(23).3934-3945.

536 Zhou C.Z, Confalonieri F, Medina N, Zivanovic Y, Esnault C, Yang T, Jacquet M, Janin, J, 537 Duguet M, Perasso R, Li Z.G. 2000. Fine organization of Bombyx mori fibroin heavy chain 538 gene. Nucleic Acids Research 28(12):2413-2419.

539 
541 Figures legends

542 Figure 1. Electron micrographs of silk fibroin and sericin. A. Electron micrograph of

543 sonicated silk fibroin. B. Electron micrographic image of silk sericin.

544 Figure 2. Wound healing process in different treatment groups at post wounding day

545 11. $\mathrm{C} 1=$ Positive control (Polyfax); $\mathrm{C} 2=$ Negative control (Saline solution); $\mathrm{T} 1=5 \%$ Sericin;

$546 \mathrm{~T} 2=5 \%$ Sericin and 5\% Aloe vera gel; T3=5\% Fibroin; T4=5\% Fibroin and 5\% Aloe vera gel.

547 Figure 3. Comparison of percent wound contraction between treatment and control

548 groups. Keys: $\mathrm{C} 1=$ Positive control (Polyfax); $\mathrm{C} 2=$ Negative control (Saline solution); $\mathrm{T} 1=5 \%$

549 Sericin; T2=5\% Sericin and 5\% Aloe vera gel; T3=5\% Fibroin; T4=5\% Fibroin and 5\% Aloe

550 vera gel. 'a' indicates the significance difference between $\mathrm{C} 2$ and $\mathrm{T} 3$, ' $\mathbf{b}$ ' indicates the

551 significance difference between C2 and T4, Each bar represents the mean values and SEM of six

552 replicates. Statistical icons: $a, b=p \leq 0.05$.

553 Figure 4. H \& E staining showing the histological changes in diabetic mice skin at post-

554 wounding day 10 in different treatment groups. Magnifications of 10X. Scale bar $=100 \mu \mathrm{m}$.

$555 \mathrm{C} 1=$ Positive control (Polyfax); $\mathrm{C} 2=$ Negative control (Saline solution); $\mathrm{T} 1=5 \%$ Sericin; $\mathrm{T} 2=5 \%$

556 Sericin and 5\%Aloe vera gel; T3=5\% Fibroin; T4=5\% Fibroin and 5\%Aloe vera gel. 


\section{Figure 1}

Figure 1. Electron micrographs of silk fibroin and sericin.

A. Electron micrograph of sonicated silk fibroin. B. Electron micrographic image of silk sericin.
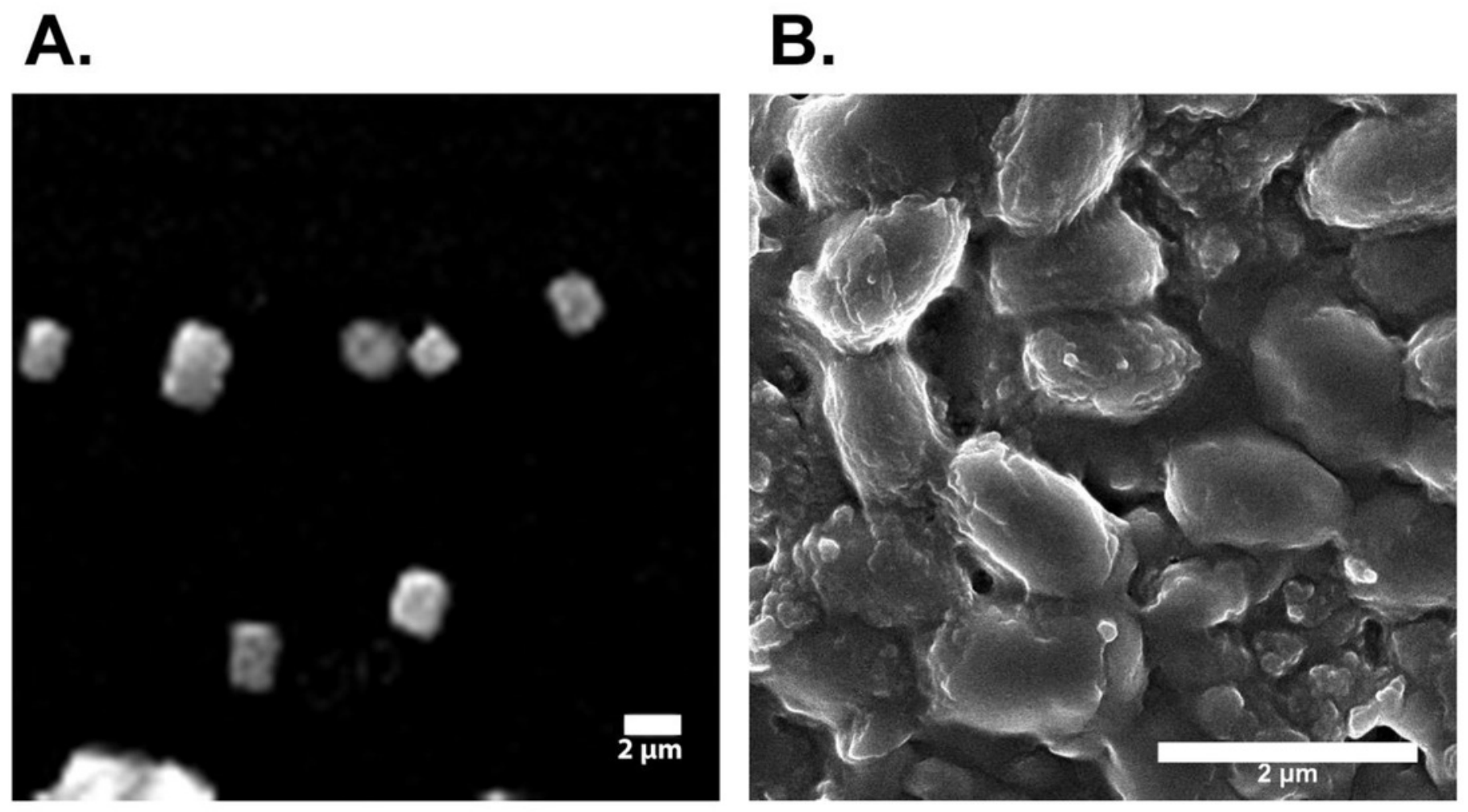
Figure 2

Figure 2. Wound healing process in different treatment groups at post wounding day 11 .

$\mathrm{C} 1=$ Positive control (Polyfax); $\mathrm{C} 2=$ Negative control (Saline solution); $\mathrm{T} 1=5 \%$ Sericin; $\mathrm{T} 2=5 \%$

Sericin and 5\%Aloe vera gel; T3=5\% Fibroin; T4=5\% Fibroin and 5\% Aloe vera gel.

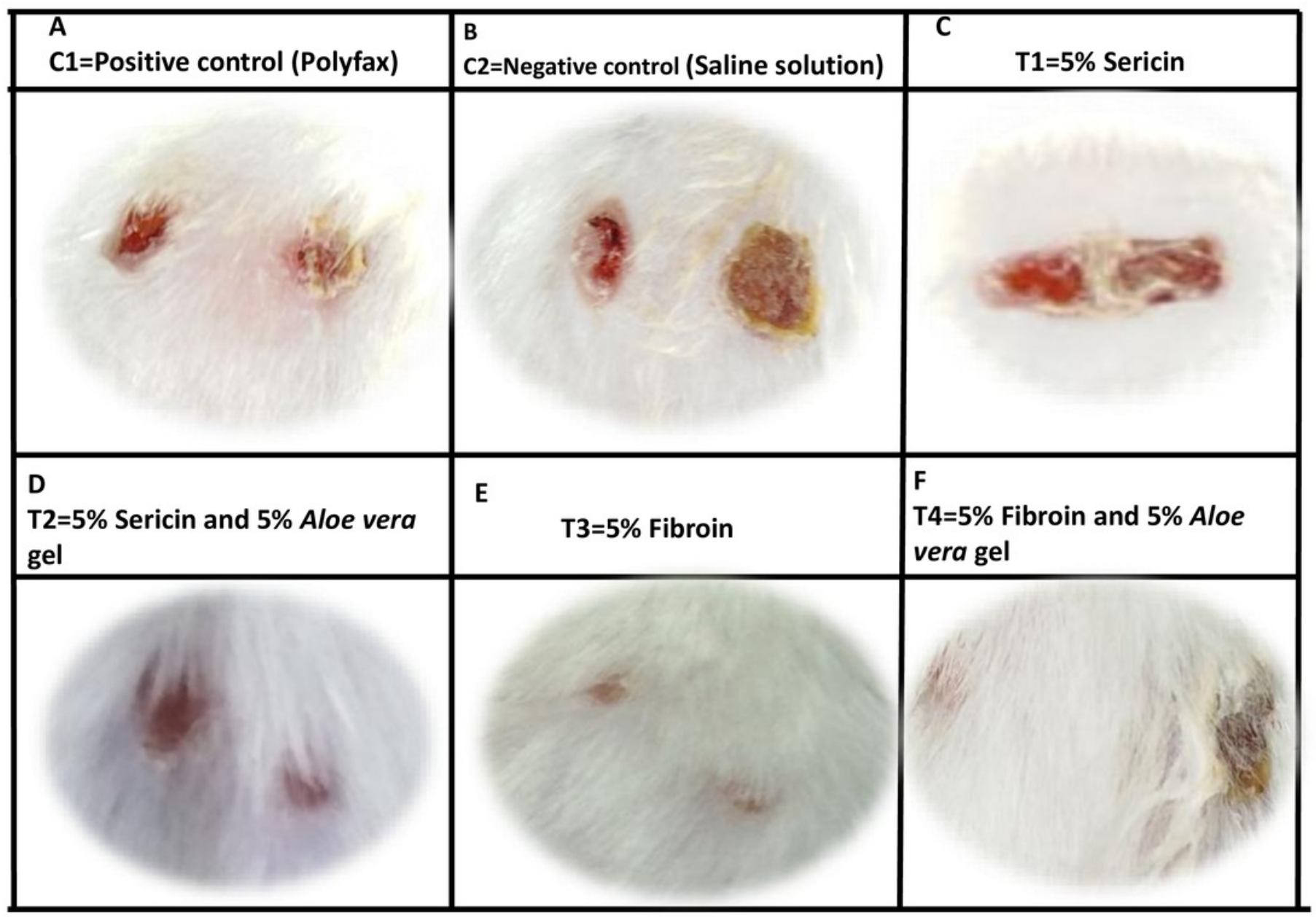


Figure 3

Figure 3. Comparison of percent wound contraction between treatment and control groups.

Keys: $\mathrm{C} 1=$ Positive control (Polyfax); $\mathrm{C} 2=$ Negative control (Saline solution); $\mathrm{T} 1=5 \%$ Sericin; T2 $=5 \%$ Sericin and 5\% Aloe vera gel; T3=5\% Fibroin; T4=5\% Fibroin and 5\% Aloe vera gel. ' $\mathbf{a}$ ' indicates the significance difference between C2 and T3, ' $\mathbf{b}$ ' indicates the significance difference between C2 and T4, Each bar represents the mean values and SEM of six replicates. Statistical icons: $a, b=p \leq 0.05$.

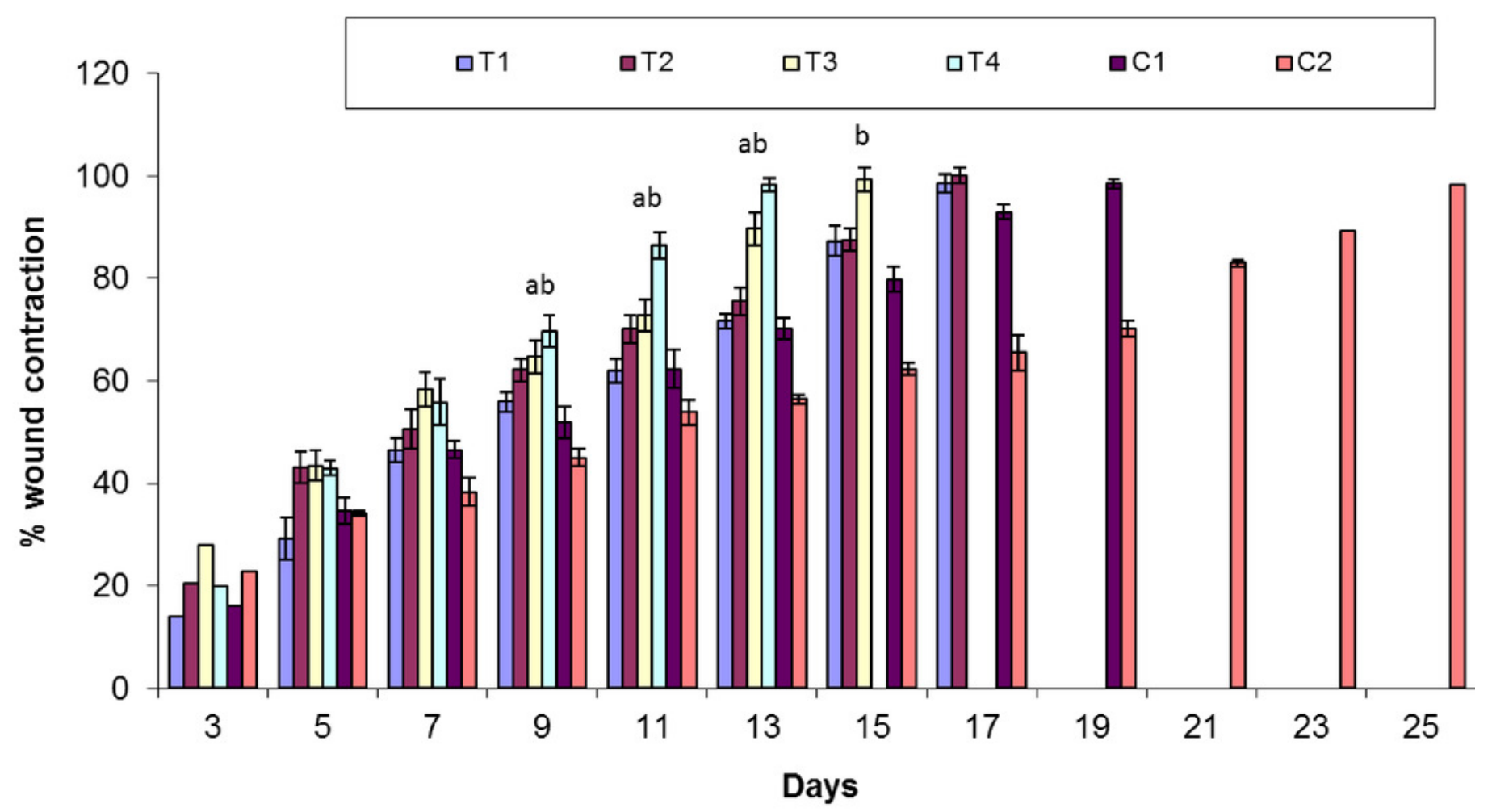


Figure 4

Figure 4. $\mathrm{H} \& \mathrm{E}$ staining showing the histological changes in diabetic mice skin at postwounding day 10 in different treatment groups.

Magnifications of 10X. Scale bar $=100 \mu \mathrm{m} . \mathrm{C} 1=$ Positive control (Polyfax); $\mathrm{C} 2=$ Negative control (Saline solution); T1=5\% Sericin; T2=5\% Sericin and 5\%Aloe vera gel; T3=5\% Fibroin; $\mathrm{T} 4=5 \%$ Fibroin and 5\%Aloe vera gel.

\begin{tabular}{|l|l|l|l|}
\hline A. C1=Positive control (Polyfax) & B.C2=Negative control (Saline solution) & C. T1=5\% Sericin \\
\hline B & B & & B \\
\hline Thin epithelium & & & \\
\hline & & & \\
\hline
\end{tabular}




\section{Table 1 (on next page)}

List of major and minor compounds detected through the GC-MS analysis of Aloe vera gel. 
Table 1: List of major and minor compounds detected through the GC-MS analysis of Aloe vera gel.

\begin{tabular}{|c|c|c|c|}
\hline & Compound name & $\begin{array}{l}\text { Molecular } \\
\text { formula }\end{array}$ & $\begin{array}{l}\text { Molecular } \\
\text { weight }\end{array}$ \\
\hline 1 & $\begin{array}{l}\text { 2,4:3,5:6,7-Tri-O-benzylidene-1-deoxy-d- } \\
\text { gluco-d-gulo-heptitol }\end{array}$ & $\mathrm{C}_{28} \mathrm{H}_{28} \mathrm{O}_{6}$ & 460 \\
\hline 2 & Glycine & $\mathrm{C}_{36} \mathrm{H}_{69} \mathrm{NO}_{6} \mathrm{Si}_{3}$ & 695 \\
\hline 3 & $\begin{array}{l}\text { Di-1,3-xylyl-24-crown-6, 5,5'-dimethyl-2,2'- } \\
\text { bis(2-propenyloxy) }\end{array}$ & $\mathrm{C}_{32} \mathrm{H}_{44} \mathrm{O}_{8}$ & 556 \\
\hline 4 & $\begin{array}{l}\text { Decyl .alpha.-d-galactoside, 2,4,6-detrioxy-3- } \\
\text { O-benzyl-4,6-S-dibenzylthio }\end{array}$ & $\mathrm{C}_{37} \mathrm{H}_{50} \mathrm{O}_{3} \mathrm{~S}_{2}$ & 606 \\
\hline 5 & $\begin{array}{l}\text { 1,5-Anhydro-2,3-dibenzoyl-4,6-O-dibenzyl-d- } \\
\text { glutitol }\end{array}$ & $\mathrm{C}_{34} \mathrm{H}_{32} \mathrm{O}_{7}$ & 552 \\
\hline 6 & Colchicine & $\mathrm{C}_{31} \mathrm{H}_{31} \mathrm{NO}_{7}$ & 529 \\
\hline 7 & Stannane, bis (pentafluorophenyl) diphenyl & $\mathrm{C}_{24} \mathrm{H}_{10} \mathrm{~F}_{10} \mathrm{Sn}$ & 608 \\
\hline 8 & Inositol & $\mathrm{C}_{24} \mathrm{H}_{60} \mathrm{O}_{6} \mathrm{Si}_{6}$ & 612 \\
\hline 9 & Galactonic acid & $\mathrm{C}_{24} \mathrm{H}_{60} \mathrm{O}_{7} \mathrm{Si}_{6}$ & 628 \\
\hline 10 & Myo-Inositol & $\mathrm{C}_{24} \mathrm{H}_{60} \mathrm{O}_{6} \mathrm{Si}_{6}$ & 612 \\
\hline 11 & Isopropyl Myristate & $\mathrm{C}_{17} \mathrm{H}_{34} \mathrm{O}_{2}$ & 270 \\
\hline 12 & 9-Octadecenoic acid & $\mathrm{C}_{21} \mathrm{H}_{38} \mathrm{O}_{4}$ & 354 \\
\hline 13 & Dodecanoic acid & $\mathrm{C}_{15} \mathrm{H}_{30} \mathrm{O}_{2}$ & 242 \\
\hline 14 & Hexadecanoic acid, methyl ester & $\mathrm{C}_{17} \mathrm{H}_{34} \mathrm{O}_{2}$ & 270 \\
\hline 15 & 10-Octadecenoic acid & $\mathrm{C}_{19} \mathrm{H}_{36} \mathrm{O}_{2}$ & 296 \\
\hline 16 & Pentadecanoic acid, 14-methyl-, methyl ester & $\mathrm{C}_{17} \mathrm{H}_{34} \mathrm{O}_{2}$ & 270 \\
\hline 17 & 12-Octadecenoic acid, methyl ester & $\mathrm{C}_{19} \mathrm{H}_{36} \mathrm{O}_{2}$ & 296 \\
\hline
\end{tabular}




\section{Table 2 (on next page)}

List of five major compounds with their retention time (RT) and peak area (\%) detected through the GC-MS study of Aloe vera gel. 
1 Table 2: List of five major compounds with their retention time (RT) and peak area (\%)

2 detected through the GC-MS study of Aloe vera gel.

\begin{tabular}{|c|c|c|c|c|c|}
\hline No & RT & Name of the compound & $\begin{array}{l}\text { Molecular } \\
\text { formula }\end{array}$ & $\begin{array}{l}\text { Molecular } \\
\text { weight }\end{array}$ & $\begin{array}{l}\text { Peak area } \\
(\%)\end{array}$ \\
\hline 1 & 13.47 & $\begin{array}{l}\text { 2,4:3,5:6,7-Tri-O-benzylidene-1- } \\
\text { deoxy-d-gluco-d-gulo-heptitol }\end{array}$ & $\mathrm{C}_{28} \mathrm{H}_{28} \mathrm{O}_{6}$ & 460 & 10.83 \\
\hline 2 & 13.443 & $\begin{array}{l}\text { Stannane, bis } \\
\text { (pentafluorophenyl) diphenyl. }\end{array}$ & $\mathrm{C}_{24} \mathrm{H}_{10} \mathrm{~F}_{10} \mathrm{Sn}$ & 608 & 10.77 \\
\hline 3 & 17.879 & Isopropyl Myristate & $\mathrm{C}_{17} \mathrm{H}_{34} \mathrm{O}_{2}$ & 270 & 15.98 \\
\hline 4 & 18.894 & 9-Octadecenoic acid & $\mathrm{C}_{21} \mathrm{H}_{38} \mathrm{O}_{4}$ & 354 & 23.90 \\
\hline 5 & 20.531 & 10-Octadecenoic acid & $\mathrm{C}_{19} \mathrm{H}_{36} \mathrm{O}_{2}$ & 296 & 38.52 \\
\hline
\end{tabular}

3 